\title{
Female genital tuberculosis: a clinicopathological study
}

\section{Rathnamala M. Desai*, Sunil Kumar, Usha Brindini}

\begin{abstract}
Department of Obstetrics and Gynaecology, Sri Dharmasthala Manjunatheshwara College of Medical Sciences and Hospital, Dharwad, Karnataka, India
\end{abstract}

Received: 21 June 2016

Accepted: 09 July 2016

\section{*Correspondence:}

Dr. Rathnamala M. Desai,

E-mail: rathnamalamdesai@yahoo.co.in

Copyright: ( ) the author(s), publisher and licensee Medip Academy. This is an open-access article distributed under the terms of the Creative Commons Attribution Non-Commercial License, which permits unrestricted non-commercial use, distribution, and reproduction in any medium, provided the original work is properly cited.

\section{ABSTRACT}

Background: The aim of this study was to describe the various clinical presentations of female genital tuberculosis and study the different methods of diagnosis and treatment.

Methods: A study of all cases of female genital tuberculosis diagnosed in the last five years was done.

Results: Female genital tuberculosis was diagnosed in 25 cases over a period of five years. Majority of the women $(60 \%)$ were in the younger age group. Most of the women $(60 \%)$ presented with infertility. Twelve (48\%) women had primary infertility and $3(12 \%)$ had secondary infertility. Nine $(36 \%)$ women had secondary amenorrhea. Five (20\%) women complained of abdominal pain. Thirteen (52\%) women who underwent diagnostic hysterolaparoscopy as a part of evaluation for infertility were diagnosed to have genital tuberculosis. Genital tuberculosis was diagnosed by endometrial biopsy or biopsy from the tubercles if present. Genital tuberculosis was diagnosed by laparotomy in 4 cases. Four women underwent salpingectomy. Two women underwent excision of Tubo-ovarian mass. One woman had intestinal resection. All cases were treated with anti-tubercular drugs.

Conclusions: Genital tuberculosis frequently causes infertility and secondary amenorrhea. In a country like India where tuberculosis is endemic a clinician should have a high degree of suspicion when evaluating cases of infertility and secondary amenorrhea.

Keywords: Genital tuberculosis, Infertility, Secondary amenorrhea

\section{INTRODUCTION}

Tuberculosis is one of the leading causes of mortality amongst the communicable diseases worldwide. ${ }^{1}$ There is a resurgence of tuberculosis since the 1980's due to the HIV epidemic and emergence of drug resistant strains. Tuberculosis and HIV together, are the commonest cause of infectious disease associated mortality worldwide. Tuberculosis is found in one third of the HIV infected individuals. $^{2}$

In India tuberculosis is the leading cause of mortality. Every ninety seconds one person dies due to tuberculosis. Approximately a thousand people die due to tuberculosis every day. ${ }^{3}$ Tuberculosis is responsible for long term morbidity as well.
Tuberculosis commonly affects the pulmonary system. However extra-pulmonary tuberculosis is not uncommon. Female genital tuberculosis is rare in the developed world. Genital tuberculosis is an important cause of infertility in developing countries. The incidence of genital tuberculosis is highest in Africa and Asia. ${ }^{4}$ Female genital tuberculosis is of significant clinical importance in India.

Genital tuberculosis, caused by Mycobacterium Tuberculosis is almost always secondary to tuberculosis elsewhere in the body. The spread of the disease is from the lungs or abdomen by haematogenous route. The fallopian tubes are the commonest site to be affected resulting in endo salpingitis. Direct spread from the intestines or peritoneum can cause exosalpingitis. Tuberculosis spreads from the tubes to the endometrium in fifty percent of the cases. Ovaries may be involved by 
direct spread or via the lymphatics. Involvement of the vulva vagina and cervix can occur rarely, by infection caused by sexual contact with an infected partner. ${ }^{5}$

\section{METHODS}

This study is a retrospective study of the clinical presentation of female genital tuberculosis over a five year period. The data was collected from the records of all the women diagnosed as cases of genital tuberculosis.

The data regarding age, symptoms, clinical signs, the investigations and the histopathological reports were analysed.

\section{RESULTS}

Twenty five women diagnosed to be having genital tuberculosis were included in this study. Only three patients $(12 \%)$ had past history of pulmonary tuberculosis. Genital tuberculosis affects the adolescent and young women. Four women (16\%) were less than 20 years; eleven women (44\%) were between 20-29 years of age. Six women (24\%) were between 30-39 years, two women $(8 \%)$ were $40-49$ years, and two women $(8 \%)$ were more than 50 years of age (Table 1 ).

Table 1: Age incidence.

\begin{tabular}{|lll|}
\hline A ge (years) & Number & $\%$ \\
\hline Less than 20 yrs & 4 & 16 \\
\hline $21-29$ yrs & 11 & 44 \\
\hline $30-39$ yrs & 6 & 24 \\
\hline $40-49$ yrs & 2 & 8 \\
\hline More than 50 yrs & 2 & 8 \\
\hline
\end{tabular}

The commonest symptom was primary infertility. Twelve women $(48 \%)$ had primary infertility. The second commonest symptom was secondary amenorrhoea which was seen in nine women $(36 \%)$ and five women $(20 \%)$ suffered from chronic abdominal pain. Three women $(12 \%)$ had secondary infertility, three women $(12 \%)$ had menstrual disturbances, two women (8\%) were asymptomatic, one woman (4\%) had white discharge per vagina and one woman had $(4 \%)$ pruritus vulvae (Table 2).

On clinical examination four (16\%) patients presented with adenexal mass, two patients $(8 \%)$ had an unhealthy cervix and one patient (4\%) presented with mass per abdomen. Ultrasound examination revealed tubo-ovarian mass in eight patients $(32 \%)$, one woman $(4 \%)$ had an irregular uterine cavity and one woman $(4 \%)$ had endometrial calcification.

Of the 25 patients, thirteen women (52\%) underwent laparoscopy, four (16\%) underwent laparotomy, two $(8 \%)$ underwent an endometrial biopsy and two cases $(8 \%)$ had a cervical biopsy. Two cases $(8 \%)$ who were asymptomatic and were diagnosed post-operatively after vaginal hysterectomy with pelvic floor repair for uterine prolapse. One woman (4\%) had tubercular pelvic lymphadenitis and one woman (4\%) had associated intestinal tuberculosis.

Table 2: Symptoms of genital tuberculosis.

\begin{tabular}{|ll|l|}
\hline Symptoms & Number & $\%$ \\
\hline Primary infertility & 12 & 48 \\
\hline Secondary amenorrhoea & 9 & 36 \\
\hline Abdominal pain & 5 & 20 \\
\hline Secondary infertility & 3 & 12 \\
\hline Menstrual disturbances & 3 & 12 \\
\hline White discharge & 1 & 4 \\
\hline Pruritus vulvae & 1 & 4 \\
\hline Asymptomatic & 2 & 8 \\
\hline
\end{tabular}

Histopathology revealed tubercular endometritis in eight cases $(32 \%)$, tubercular salpingitis in seven cases $(28 \%)$, tubercular cervicitis in four cases $(16 \%)$, associated intestinal tuberculosis in two cases (8\%), tubercular vulvitis one case(4\%) and tubercular lymphadenitis in one case $(4 \%)$. All patients were treated with antitubercular drugs.

\section{DISCUSSION}

India is one of the twenty two countries with a high burden of tuberculosis. Tuberculosis is an important cause for mortality and morbidity in India. Female genital tuberculosis is usually secondary to a primary focus elsewhere in the body. It usually spreads by the haematogenous route. Genital tuberculosis can rarely occur as primary infection when a woman has sexual intercourse with a male partner suffering from genital tuberculosis. ${ }^{6}$ Genital tuberculosis manifests in two to twenty percent of patients with pulmonary tubercolosis. ${ }^{6,7}$ In the developed countries genital tuberculosis is the causative factor in $1 \%$ of infertile women, whereas in India genital tuberculosis is the causative factor in $18 \%$ of infertile women. ${ }^{8,9}$

Mycobacterium tuberculosis enters through the respiratory passage and disseminates to various organs by lymphatic and haematogenous spread. Female genital tract is an important site of spread of the disease. The disease is quiescent and often asymptomatic. The infection may remain silent or may flare-up when immunity is reduced. ${ }^{10}$

Tuberculosis almost always causes salpingitis and tubal block (92-100\%), endometritis and secondary amenorrhoea in half the cases (50\%). Ovarian involvement is a late feature (10-30\%). The cervix is involved in $5 \%$ cases and vagina and vulva are rarely involved $(1 \%) .^{11,12}$ Tuberculosis also causes pelviperitoneal adhesions. Tubercular salpingitis causes 
exudative changes followed by adhesions. The tissues heal by fibrosis and calcification.

Genital tuberculosis usually presents in the young adult. Increased blood circulation and hormone dependence of the genital tract after sexual maturity may explain why genital tuberculosis affects the young adult. ${ }^{13}$

There is a strong relationship between female genital tuberculosis and infertility. Genital tuberculosis should be considered as a diagnosis in every case of infertility in endemic areas. ${ }^{14}$ The incidence of infertility in women with genital tuberculosis ranges from 10 to $85 \%$. Genital tuberculosis can be asymptomatic or the woman may have nonspecific symptoms. Several studies have shown that the commonest symptoms of genital tuberculosis are infertility and chronic pelvic pain. ${ }^{15}$ Genital tuberculosis invariably involves the fallopian tubes and causes tubal block. Tubercular endometritis occurs in $50 \%$ of the cases and interferes with implantation. Tubercular oophoritis causes ovulatory defects. ${ }^{16-18}$ Uterine synechae causes secondary amenorrhoea.

Genital tuberculosis causes menstrual disturbances. Oligomenorrhoea occurs in $54 \%$ of women, menorrhagia in 19\%, amenorrhoea in $14.3 \%$ of women and postmenopausal bleeding in $1.6 \%$ of women. Tuboovarian mass is seen $19.8 \%$ of the women. ${ }^{19}$

Female genital tuberculosis is difficult to diagnose because there are no specific clinical features. Often there is difficulty in obtaining material for bacteriological examination. All cases of infertility in endemic areas should be investigated for genital tuberculosis. Women with ascites or pelvic masses should be evaluated for tuberculosis. $^{20}$

Several investigations are done to diagnose pelvic tuberculosis like hystero-salpingography, endometrial biopsy and cervical biopsy. Hystero-salpingography is a useful investigation in low resource settings where laparoscopy is unavailable or unaffordable. Findings like salpingitis isthmica nodosa, rosary bead appearance, lead pipe tubes and tobacco pouch appearance are characteristic of genital tuberculosis. Laparoscopy and laparoscopy directed biopsy are useful in diagnosis of tubercular salpingitis. Endometrial TB-PCR is a useful tool for diagnosis of genital tuberculosis. ${ }^{21}$

Genital tuberculosis is mainly treated by anti-tubercular drugs for 6-9 months. Surgery is indicated for unresolved tubo-ovarian masses or intestinal obstruction. Early diagnosis and treatment with anti-tubercular drugs may restore fertility in women with minimal damage to the tubes and endometrium. However, with advanced disease with tubercular salpingitis or endometritis conception is rare. The outcome is poor in tuboplasty or even in-vitro fertilization. ${ }^{22}$ Female genital tuberculosis is an important cause of reproductive morbidity and infertility, particularly in young women. A strong clinical suspicion is important for early diagnosis and treatment of genital tuberculosis. Doctors in endemic areas like India need to be trained to be tuberculosis minded. ${ }^{23}$

\section{CONCLUSION}

Genital tuberculosis frequently causes infertility and secondary amenorrhea. In a country like India where tuberculosis is endemic a clinician should have a high degree of suspicion when evaluating cases of infertility and secondary amenorrhea.

Funding: No funding sources

Conflict of interest: None declared

Ethical approval: The study was approved by the Institutional Ethics Committee

\section{REFERENCES}

1. Frieden TR, Sterling TR, Munsiff SS, Walt CJ, Dye C. Tuberculosis. Lancet. 2003;362:887-99.

2. Zajaczkowski T. Genitourinary tuberculosis: historical and basic science review: past and present. Central European Journal of Urology. 2012;65(4):182-7.

3. Dye C. India's leading role in tuberculosis epidemiology and control. Indian $\mathrm{J}$ Med Res. 2006;123(4):481-4

4. Dye C, Watt CJ, Bleed DM, Hosseini SM, Raviglione MC. Evolution of tuberculosis control and prospects for reducing tuberculosis incidence, prevalence and deaths globally. JAMA. 2005;293:2767-75.

5. Shah HU, Sannananja B, Baheti AD, Udare AS, Badhe PV. Hysterosalpingography and ultrasonography findings of female genital tuberculosis. Diagnostic and Interventional Radiology. 2015;21(1):10-5.

6. Sutherland AM, Glen ES, Macfarlane JR. Transmission genitourinary tuberculosis. Health Bull, 1982.

7. Nogales OF, Tarancon I, Nogales FF. The pathology of female genital tuberculosis a 31- year studv of 1436 cases. Obstet Gynecol. 1979;53(4):422-8.

8. Muir DG, Belsey MA. Pelvic inflammatory disease and its consequences in the developing world. Am J Obstet Gynecol. 1980;138:913-28.

9. Schaefer G. Female genital tuberculosis. Clin Obstet Gynecol. 1976;19:223-39.

10. Arora VK, Gupta R, Arora R. Female genital tuberculosis - need for more research. Indian $\mathbf{J}$ Tuberc. 2003;50:9-11.

11. Crofton J, Horne N, Miller F. Clinical tuberculosis. 1 st ed. London: Macmillan. 1992. pp. 502-10.

12. Klein TA, Richmond JA, Mishell DR. Pelvic tuberculosis. Obstet Gynecol. 1976;48:99-104.

13. Chowdhary NN. Overview of tuberculosis of the female genital tract. J Indian Med Assoc. 1996;94:345-61. 
14. Namavar Jahromi B1, Parsanezhad ME, GhaneShirazi R. Female genital tuberculosis and infertility.Int J Gynaecol Obstet. 2001;75(3):269-72.

15. Qureshi RN1, Samad S, Hamid R, Lakha SF.Female genital tuberculosis revisted.J Pak Med Assoc. 2001;51(1):16-8.

16. Bapna N, Swarankar M, Kotia N. Genital tuberculosis and its consequences on subsequent fertility. J Obstet Gynecol India. 2005;55:534-7.

17. Varma TR. Genital tuberculosis on subsequent fertility. Int J Gyneacol Obstet. 1991;35(1):1-11.

18. Tripathy SN, Tripathy SN. Infertility and pregnancy outcome in female genital tuberculosis Int $\mathbf{J}$ Gynaecol Obstet. 2002;76(2):159-63.

19. Samal S, Gupta U, Agarwal P. Menstrual disorder in genital tuberculosis. J Indian Med Assoc. 2000;98(3):126-9.

20. Lortkipanidze GG, Vashakidze LM, Mamaladze TT, Gudzhabidze NB. Implication of laparoscopy in diagnostics of genital tb among women through cytohistological testing of bioptic specimen Georgian Med News. 2015;238:39-45.

21. Jindal UN, Bala Y, Sodhi S, Verma S, Jindal S. Female genital tuberculosis: early diagnosis by laparoscopy and endometrial polymerase chain reaction. Int J Tuberc Lung Dis. 2010;14(12):162934 .

22. Ishrat $\mathrm{S}$, Fatima $\mathrm{P}$ Genital tuberculosis in the infertile women - an update. Mymensingh Med J. 2015;24(1):215-20.

23. Ghosh K, Ghosh K, Chowdhury JR. Tuberculosis and female reproductive health. Postgrad Med 2011;57(4):307-13.

Cite this article as: Desai RM, Kumar S, Brindini U. Female genital tuberculosis: a clinicopathological study. Int J Reprod Contracept Obstet Gynecol 2016;5:2780-3. 